\title{
Critical Determinants of Supply of Services in the Nigeria Formal Sector Social Health Insurance Programme
}

\author{
Obi Ikechukwu Vincent ${ }^{1, ~ *, ~ O k o r o n k w o ~ I j e o m a ~ L e w e c h i ~}{ }^{1,2}$, Adi Jesse Ashumate ${ }^{3}$ \\ ${ }^{1}$ Department of Health Management and Administration, University of Nigeria, Enugu, Nigeria \\ ${ }^{2}$ Department of Nursing Services, University of Nigeria, Enugu, Nigeria \\ ${ }^{3}$ Department of Health Services, Federal University Wukari, Jalingo, Nigeria
}

Email address:

ivcobiayahoo.com (O. I. Vincent)

${ }^{*}$ Corresponding author

\section{To cite this article:}

Obi Ikechukwu Vincent, Okoronkwo Ijeoma Lewechi, Adi Jesse Ashumate. Critical Determinants of Supply of Services in the Nigeria Formal Sector Social Health Insurance Programme. European Journal of Clinical and Biomedical Sciences. Vol. 5, No. 6, 2019, pp. 79-84. doi: $10.11648 /$ j.ejcbs.20190506.12

Received: November 21, 2019; Accepted: December 13, 2019; Published: December 24, 2019

\begin{abstract}
Introduction: The principle underpinning the Supply of health insurance services in Nigeria is that as prices increases, the healthcare provider makes more profit and will be motivated to provide more health insurance services to the enrollees. These supplies of health insurance services are therefore influenced by critical determinants that will either make the provider to supply health insurance services or withhold it. Therefore, there is a need to look at those critical factors that can hinder the supply of services in the programme. This study sets out to examine the effect of identified critical determinants on supply of services and also show how much these critical determinants can collectively predict this supply of services. Design/Methodology: This is a cross sectional study using a quantitative approach. Sample size was determined using Cochran formular and calculated sample size was forty six (46). Multistage sampling technique was adopted. Variables were analyzed using descriptive statistics and linear regression method with SPSS version 11. Result: The critical determinants of reimbursement structure, tariff structure, facility number of enrollees and cost of hospital consumables studied had positive impact on the supply of service but the impact of cost of hospital consumable was insignificant $(>0.5)$. Similarly, $95 \%$ of changes in the supply of services can be accounted for significantly by the independent variables in this study $(\mathrm{p}=0.000)$. Conclusion: Evidences from this study have shown that most of the identified critical determinants studied had significant effect and also collectively could account significantly for changes in the supply of services and so therefore there is a need to properly address these factors so as to achieve the set out objectives in the programme.
\end{abstract}

Keywords: Supply of Health Insurance Services, Reimbursement Structure, Tariff Structure, Hospital Consumables, Facility Enrollee Number

\section{Introduction}

Supply is the amount of healthcare services a provider can supply in the healthcare market at a given cost and in a given time [1]. The principle underpinning the supply of healthcare services is that as the price increases, the provider makes more profit and then will be motivated to offer other types of healthcare services to enrollees [1].

A supply curve therefore will show an increase in price of healthcare services with a corresponding increase in more services that will be rendered to the enrollees. This curve slopes upwards from left to right and three reasons accounts for this condition [1]. The first reason is the profit motive of the healthcare provider who raises the price of healthcare services as a result of increased enrollee demand; it becomes imperative for the provider to venture into other areas of healthcare services. The second reason is the cost of rendering healthcare services; when a provider provides more healthcare services, there is a tendency for the cost of providing healthcare services to rise; therefore, there is a need to increase the cost of procuring healthcare services. This condition may be due to diminishing return because 
more healthcare services are being offered to enrollees. The third reason is the entrants of new healthcare providers into the healthcare market. As the profit increases, it will create an incentive for more healthcare providers to enter the healthcare market thereby leading to an increase in the total amount of healthcare services being supplied.

However, in the supply of health insurance services in Nigeria, the supply curve fails to follow the normal trajectory because these health insurance services that are being supplied in the health insurance market are viewed to be of poor quality, unsafe and also inaccessible to majority of the Nigerian people $[2,3]$. Most of the hospitals that offer health insurance services in the healthcare market are confined mostly in the urban centres with people living in these areas having more access to healthcare than those living in the rural areas [4, 3]. Also, in the Nigeria healthcare market, the hospitals that offer health insurance services are not organized and properly regulated, they consists of many small medical facilities that are owned by private medical practitioners $[5,2]$. Most of the hospitals have less than fifty beds with very minimal facilities that cannot render quality healthcare services to enrollees [2]; this therefore affects the services being rendered to the patients in these centres. Similarly, there are gross shortage of doctors, nurses and other clinical and non-clinical staff, who are important links in the health insurance service delivery [6-7]. The salaries of these health workers are not attractive enough to retain the talented medical workers in the country [8-9]. Brian drain has therefore become a major public concern with large number of doctors, nurses and other healthcare professionals leaving the Nigeria shores for better opportunities outside, mainly to USA and Europe thereby causing supply gap in the country with attendant effect on service delivery $[10,2]$. Other challenges observed that are militating against supply of quality health insurance services include incessant strike action by health workers, lack of political will as exhibited by successive government in carrying out established planned actions which is apparent in infrastructural deficit, as observed in the poor state of various healthcare facilities across the nation [11]. This situation may directly be linked with the consistent underfunding of the health sector and attendant mismanagement of appropriated funds and further compounded by increasing population. Thus, healthcare workers have to make do with obsolete equipment and electricity challenges. This situation definitely impacts on the quality of output and efficiency in the health insurance industry.

In addition, healthcare providers' behavior in the programme has invariably influenced the supply curve. The operational guidelines of the programme in Nigeria indicated that claims submitted by healthcare providers should be settled fourteen days after the submission [12]; therefore delays or non settlement of these claims as noticed in the programme have greatly influenced healthcare providers' behavior in service provision [13]. Similarly, delayed settlement of claims have made healthcare providers unable to procure drugs and non-drug supplies for their facilities and as a result enrollees that access care at the facilities were made to pay out of pocket for these drugs and non-drug supplies [14]. Other consequences of the delay in claims settlement is that healthcare providers prefer enrollees that would make out of pocket payments for services which may result in catastrophic spending and prolonged waiting time for enrollees that cannot pay from out of pocket [14]. Similarly, the provider payment mechanism has also influenced healthcare providers' supply of services in the health insurance industry and as a result each provider payment mechanism has led to healthcare providers having different kinds of incentive in order to provide health insurance services [15].

These determinants that influence healthcare provider supply of health insurance services if addressed properly by relevant authorities will definitely lead to universal health coverage being achieved as envisioned by the government of Nigeria. This study therefore aims at looking at those identified critical determinants of supply of health insurance services with a view to assessing their effect and how much they can account for the changes in the supply of health insurance services as stipulated in NHIS operational guideline and also provide evidence-based recommendation on how to improve supply of services in the programme.

\section{Methods}

\subsection{Study Design}

The study adopted a quantitative approach in exploring the variables in this study. This approach is seen to be appropriate for this study because it aided the exploration of the effect of the explanatory variables on the dependent variable at a given time and also enabled the prediction of the dependent variable.

\subsection{Population of Study}

The study population comprised the eighty four Chief Medical Directors of accredited healthcare providers operating in Enugu state [16].

\subsection{Sample Size}

The size of the sample was calculated using Cochran's formula [17]. Maximum variability was desired because little information is known about supply of services in the programme and as a result this formular is seen to be appropriate for this study. A minimum sample size of 42 was calculated using estimated population proportion of 0.5 at $95 \%$ confidence interval. The sample size was increased by $10 \%$, in order to take care of attrition, thereby giving us a total sample size of 46 .

\subsection{Sampling Procedure}

A multistage sampling technique was adopted too. The healthcare providers were stratified into government-owned, privately-owned and mission-owned hospitals. The Chief Medical Directors (CMDs) in private hospitals were 75, government - owned hospitals had 5 CMDs while CMDs in the mission hospitals were 4 . The 46 Chief Medical Directors calculated as the sample size were proportionately allocated 
to the prior established stratified hospitals using the formula; sample fraction (sample size divided by study population) times relative sizes of each stratum and the following number of samples were thereafter allocated accordingly; missionowned -2 , government-owned -3 and privately-owned -41 . Finally, simple random technique was used to select allocated proportion in each stratum for the study.

\subsection{Validity of Instrument}

Face and content validity were used to assess the instrument. Ambiguous statements were removed, item relevance was evaluated using a rating scale and final statements were made from corrections.

\subsection{Reliability of Instrument}

The questionnaires were pre - tested on ten (10) Chief Medical Directors of NHIS accredited hospitals in Awka, Anambra state. A test retest method at interval of 2 weeks was carried out and the responses were computed using Pearson product moment correlation coefficient formula and coefficient reliability of 0.70 was gotten.

\subsection{Procedure for Data Collection}

Five (5) research assistants were used for questionnaire administration. The purpose of the study was fully explained to them and they were subsequently trained by the researcher for three days. The respondents were approached at their respective offices. Their permissions were sought and written consents were signed. The administration of the questionnaire was through self administered approach and it lasted for six weeks.

\subsection{Method of Data Analysis}

A linear regression analysis was used to estimate the coefficient covariance of individual variables. The linear regression method tends to describe how much a unit change in the independent variable will impact on the dependent variable. The statistical significance was set at $p<0.05$. Data were analyzed using SPSS version 11.

\subsection{Model Specification}

The model specification for the study is the linear regression model. This study adopted and modified the models by Gertler, Locay and Sanderson [18] and Ayorinde [19] to come up with the model to explain the critical determinants of supply health insurance services. Also, the modeling approach was used to estimate whether the coefficient of covariance of the independent variables fulfils the theoretical postulations on the modeling frameworks. The sign and significance of the coefficients in the model indicated the direction of the correlation between the explanatory and the dependent variables.

The model is denoted as follows:

Model: The Supply function:

$$
\log \mathrm{X}_{1}=\mathrm{Bo}_{\mathrm{O}}+\mathrm{B}_{1} \log \mathrm{X}_{2}+\mathrm{B}_{2} \log \mathrm{X}_{3}+\mathrm{B}_{3} \log \mathrm{X}_{4}+\mathrm{B}_{4} \log \mathrm{X}_{5}+\mathrm{U}
$$

Where:

Log X1: Provider Supply of services as prescribed by NHIS (dependent variable)

$\log \mathrm{X}_{2}$ : Tariff structure

$\log \mathrm{X}_{3}$ : Cost of hospital consumables

$\log \mathrm{X}_{4}$ : Reimbursement structure

Bo: Intercept

$\mathrm{U}$ : Error term

$\log \mathrm{X}_{5}$ : Facility enrollee number

On apriori, it will be expected that the signs and magnitude of parameters coefficients will be positive such that $\mathrm{B}_{1}, \mathrm{~B}_{2}$,

$$
\mathrm{B}_{3} \text { and } \mathrm{B}_{4}>0
$$

\subsection{Ethical Consideration}

Ethics Committee of State Ministry of Health, Enugu approved the study. Informed consents were obtained from each of the participants. With the aid of ethical approval and introduction letter from the Head of Department of Health Administration and Management, administrative permit was obtained from the Management of the hospitals to administer the questionnaire.

\section{Result}

Out of the forty six (46) questionnaires administered, forty two (42) questionnaires were correctly filled and retrieved giving a response rate of $91 \%$.

\subsection{Response of Providers to Their Supply of Services as Prescribed by NHIS Operational Guideline}

\begin{tabular}{|c|c|c|c|c|c|}
\hline \multirow{2}{*}{ Variables } & \multicolumn{4}{|c|}{ Providers; $n=42$} & \multirow{2}{*}{$\begin{array}{l}\text { Providers } \\
\overline{\mathbf{x}}(\sigma)\end{array}$} \\
\hline & SA & $\mathbf{A}$ & D & SD & \\
\hline Health provider offer 24 hours services & $30(71.4)$ & $12(28.6)$ & $0(0.0)$ & $0(0.0)$ & $3.71(0.46)$ \\
\hline Laboratory services are offered in the hospital & $28(66.7)$ & $14(33.3)$ & $0(0.0)$ & $0(0.0)$ & $1.33(0.48)$ \\
\hline Emergency services are offered by the health provider & $30(71.4)$ & $12(28.6)$ & $0(0.0)$ & $0(0.0)$ & $3.71(0.46)$ \\
\hline Health provider offer admission services & $40(95.2)$ & $2(4.8)$ & $0(0.0)$ & $0(0.0)$ & $3.95(0.22)$ \\
\hline Health provider refer enrollees for secondary and tertiary care promptly & $37(88.1)$ & $5(11.9)$ & $0(0.0)$ & $0(0.0)$ & $3.88(0.33)$ \\
\hline Health provider provide all the prescribed drugs & $4(9.5)$ & $6(14.3)$ & $12(28.6)$ & $20(47.6)$ & $3.14(1.00)$ \\
\hline Health provider is politeness during provision of services & $29(69.0)$ & $13(31.0)$ & $0(0.0)$ & $0(0.0)$ & $3.69(0.47)$ \\
\hline Health provider possess the required medical skills to provide the required services & $30(71.4)$ & $12(28.6)$ & $0(0.0)$ & $0(0.0)$ & $3.29(0.46)$ \\
\hline Health provider understand the plight of the enrollees while providing services & $12(28.6)$ & $8(19.0)$ & $12(28.6)$ & $10(23.8)$ & $2.48(1.15)$ \\
\hline \multirow[t]{2}{*}{ Health provider attend to health insurance enrollees promptly } & $2(4.8)$ & $18(42.9)$ & $14(33.3)$ & $8(19.0)$ & $2.67(0.85)$ \\
\hline & & \multicolumn{3}{|c|}{ Grand Overall Mean (Standard Deviation) } & $3.19(0.59)$ \\
\hline
\end{tabular}

Table 1. Response of provider to their supply of services as prescribed by NHIS operational guideline. 
Table 1 shows that none of the respondents disagreed that the healthcare providers supply $24 \mathrm{~h}$ services, laboratory services, emergency services, admission services, refer enrollees for specialist care, polite to enrollees and possess the required medical skill.

\subsection{Determinants of Supply of Health Insurance Services}

Table 2. Determinants of supply of health insurance services.

\begin{tabular}{|c|c|c|c|c|c|}
\hline \multirow{2}{*}{ Variable } & \multicolumn{5}{|c|}{ Supply Side $(n=42)$} \\
\hline & $\mathbf{S A}$ & $\mathbf{A}$ & D & SD & $\overline{\mathbf{X}}(\boldsymbol{\sigma})$ \\
\hline Tariff structure & $26(61.9)$ & $13(31.0)$ & $2(4.8)$ & $1(2.4)$ & $3.52(0.71)$ \\
\hline Reimbursement structure & $35(83.3)$ & $6(14.3)$ & $1(2.4)$ & $0(0.0)$ & $3.81(0.45)$ \\
\hline \multirow[t]{2}{*}{ Facility enrollee number } & $20(47.6)$ & $17(40.5)$ & $3(7.1)$ & $2(4.8)$ & $3.31(0.81)$ \\
\hline & & & Grand C & andard Deviation) & $3.55(0.67)$ \\
\hline
\end{tabular}

Table 2 shows that most of the respondents strongly agreed that all the variables influence supply of services but none of the respondents strongly disagreed on the effect of reimbursement on the supply of services.

\subsection{Linear Regression of Supply of Health Insurance Services and Determinants of Supply of Health Insurance Services}

Table 3. Linear regression of supply of health insurance services and determinants of supply of health insurance services.

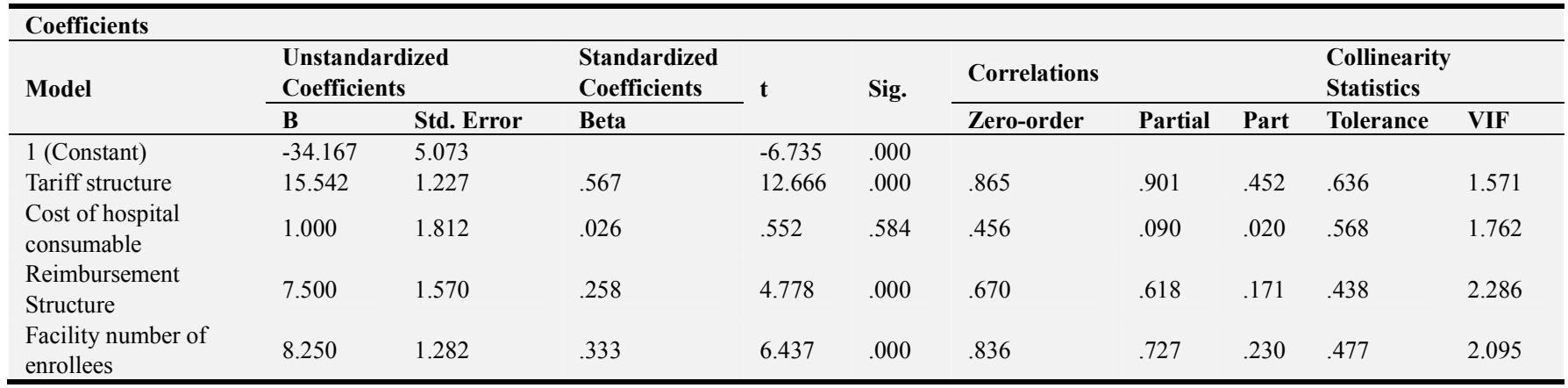

a. Dependent Variable: Supply of services as prescribed by Operational Guideline for Providers (Scored in \%).

Table 3 shows that independent variables in this study, tariff structure $(p=0.000)$, reimbursement structure $(p=0.000)$ and facility number of enrollees $(0.000)$ were critical in the determination of supply of services except price of hospital consumables $(p=0.584)$ which was not significant in the determination of supply of services.

\subsection{Model Summary of Linear Regression Analysis}

Table 4. Model summary of linear regression analysis.

\begin{tabular}{|c|c|c|c|c|c|c|c|c|c|}
\hline \multicolumn{10}{|c|}{ Model Summary } \\
\hline \multirow{2}{*}{ Model } & \multirow{2}{*}{$\mathbf{R}$} & \multirow{2}{*}{ R Square } & \multirow{2}{*}{$\begin{array}{l}\text { Adjusted R } \\
\text { Square }\end{array}$} & \multirow{2}{*}{$\begin{array}{l}\text { Std. Error of the } \\
\text { Estimate }\end{array}$} & \multicolumn{5}{|l|}{ Change Statistics } \\
\hline & & & & & R Square Change & F Change & df1 & df2 & Sig. F Change \\
\hline 1 & $.976^{\mathrm{a}}$ & .953 & .948 & 2.86571 & .953 & 186.939 & 4 & 37 & .000 \\
\hline
\end{tabular}

a. Predictors: (Constant), Facility enrollee number, Cost of hospital consumables, Tariff structure, Reimbursement structure.

Source: Researcher's computation using SPSS Version 11.

Table 4 shows that $95 \%$ of changes in the supply of services is explained by the independent variables in this study and similarly have a significant effect on the dependent variable $(\mathrm{p}=0.000)$.

Model

$$
\begin{aligned}
\log \mathrm{X} 1= & \mathrm{Bo}+\mathrm{B} 1 \log \mathrm{X} 2+\mathrm{B} 2 \log \mathrm{X} 3+\mathrm{B} 3 \log \mathrm{X} 4+ \\
& \mathrm{B} 4 \log \mathrm{x} 5+\mathrm{U}
\end{aligned}
$$

Where $\mathrm{X}_{1}=$ supply of health insurance as prescribed by operational guidelines (dependent variable)

$\mathrm{X}_{2}=$ Tariff Structure

$\mathrm{X}_{3}=$ Cost of hospital consumables
$\mathrm{X}_{4}=$ Reimbursement Structure

$\mathrm{X}_{5}=$ Facility enrollee number

$$
\text { On Apriori it is expected that } \mathrm{B}_{1}, \mathrm{~B}_{2}, \mathrm{~B}_{3}, \mathrm{~B}_{4}>0
$$

On the model for the study, the theoretical postulations indicated that the coefficients should be greater than zero. However, in this regression, all the coefficients were greater than zero thereby fulfilling the theoretical postulations which indicated that all the explanatory have positive effect on the dependent variable. 


\section{Discussion}

The supply of health insurance services in the formal sector social health insurance programme revealed that the tariff of services was positively and significantly related to the supply of health insurance. This implies that the higher the tariff in the programme, the higher the provision of health insurance. In other words, the lower the NHIS approved tariff, the lower the number of services that will be provided by the providers. Hence, as the tariff is perceived to be low, the providers will therefore be motivated to adversely select the enrollees to treat or refer to other centers for treatment thereby denying the enrollees in the programme the needed quality and efficient health insurance services. This action has led to the poor perception of enrollees about the programme in the country according to the findings in the study done by Daramola, Maduka, Adeniran and Akande [20].

Similarly, the coefficient of the cost of hospital consumables was positive but was insignificant as expected. This implies that there is a positive relationship between the supply of health insurance services and the cost of hospital consumables in the health insurance market. Therefore, it means that the higher the cost of procuring consumables and drugs for treating enrollees in the health insurance market, the higher the provision of services to enrollees all things being equal. The insignificance of this therefore might be due to the fact that the enrollees pay only $50 \%$ of the services as coinsurance for partially excluded services and $10 \%$ for copayments for only drugs. The result in this study is consistent with Wangen and Grupperud study and the theoretical predictions of Haddad and Anbaji who agreed that prices matter when monetary prices are small [21-22]. In addition, the findings in this study is inconsistent with results from Bangladesh and Nigeria which revealed that as price of procuring healthcare materials decreases in turn the supply will increase [23-24].

The sign of reimbursement structure is positive and significant, implying that there is a positive relationship between supply of health insurance and reimbursement in the health insurance market. Therefore, it means that if the providers were paid on time and also reimbursement structure is high, the supply of health insurance services will be high. The result in this study is consistent with the works of several researchers that showed delays in reimbursing providers was significant and have resulted in shaping the behaviours of the providers in the health insurance programme leading to supplier induced demand (provider moral hazard) behaviors which includes; diagnosing simple malaria as complicated malaria, over charging for drugs and services provided to enrollees, charging for services not provided, inflating number of drugs [14-15, 25]. Similarly, this study tallies with the findings of Sleverding, Onyango and Suchman study which indicated that challenge of long delays in claim reimbursement have shaped the quantity and quality of services healthcare providers renders to enrollees in the programme [26] but inconsistent with the findings of Mathijssen, Tromp, Mcbain, Ten Have and Baltussen study which showed that type of provider payment mechanism and not reimbursement was implicated in provider behavior in the programme [27].

The facility number of enrollees was positive and insignificant in this study and this positive relationship might be based on the fact that if the providers' enrollee numbers were increased, it will improve the amount of capitation accruing to the providers and fee for services claims sent out and it will invariably increase the supply of health insurance services offered to the enrollees. However, the findings in this study is in contrast with the findings of Sodzi-Tettey, Aikins, Awoonor-william and Agyepong study which mostly implicated challenges in provider payment resulting from significant delays in claims processing as the major determinant in the supply of health insurance services [28].

\section{Conclusion}

This study has shown that all the critical explanatory variables have a positive relationship with supply of health insurance services which is the dependent variable. However, it is only cost of hospital consumable that has insignificant effect on supply of health insurance services. This study therefore has helped to x-ray the root causes of the delayed and poor service delivery to the enrollees in the programme by the healthcare providers. The implicated determinants in this study which includes poor reimbursement, tariff structure, limited number of enrollees in the facilities especially among the private healthcare providers and the unstable cost of procuring hospital consumables were shown in this study to have accounted for $95 \%$ of the poor supply of services to the enrollees in the programme. These identified critical determinants might have led to providers' impatience with the enrollees and consequently enrollees' dissatisfaction as being experienced in the programme [13]. This is worrisome since it had led to delays in enrollees service utilization, poor service delivery and sometimes outright neglect of those in the programme; hence, posing a threat to the sustainability of the programme. Therefore, the findings in this study will serve as a template to enact laws that will make health insurance mandatory for all citizens which will then enable pooling of funds into the program with attendant increment in the number of enrollees in the facilities and reimbursement structure. Similarly, government owned facilities get subventions from government unlike the privately owned facilities, hence, there is need to limit primary cases to private healthcare provider and this will enhance the number of enrollees in these facilities and invariably increase pooling of fund in these private healthcare providers. In addition, extant laws should be enacted that will mandate enrollees to chose only privately owned facilities as their primary care providers (PCP) with referrals to government-owned and mission-owned hospitals in complicated health conditions. Again, the regulatory body should strengthen the extant laws that will allow for prompt payment of providers and put stricter measures to check HMOs that default in this regard. Also, this study has shown that there is a need to frequently review the NHIS tariff and 
reimbursement structures in the programme so as to reflect the present economic realities. Finally, the findings of this study will serve as a guide to National Health Insurance Scheme (NHIS) while reviewing, formulating and implementing relevant strategies towards addressing poor service delivery inherent in the programme.

\section{References}

[1] Riley, G. (2016). Theory of supply. Sourced at https//tutor2u.net/economics/reference/theory-of-supply. Accessed on 14/7/2019.

[2] Eteng, I. E., \& Utibe, E. E. (2015). The national health insurance scheme and its implication for elderly care in Nigeria. International Journal of Science and Research, 4, 2.

[3] Evans, D. B. \& Etienne, C. (2010). Health systems financing and the path to universal coverage. Bulletin of the World Health Organization, 88, 402-403.

[4] Aina, O. S., Olowa, O. W., Ibrahim, I. \& Asana, S. O. (2015). Determinants of demand for healthcare services among rural households in Ekiti state, Nigeria. Journal of Biology, Agriculture and Healthcare, 5, 7.

[5] Gustafsson-Wright, E. \& Schellekens, O. (2013). Achieving universal health coverage in Nigeria: one state at a time. Global Economy \& Development, Brooke Shearer Working Paper Series. 4 (9), 5-10.

[6] FMOH. (2006). Health care in Nigeria. Annual bulletin of the federal ministry of health Nigeria, Abuja Nigeria. Federal Ministry of Health.

[7] FMOH. (2013). Joint Annual Review of the National Strategic Health Development Plan (2009-2013), Draft Report. Abuja, Nigeria: Federal Ministry of Health.

[8] Adefolaju T. (2014). Repositioning Health Insurance in Nigeria: prospects and challenges. International Journal of Health Sciences, 2 (2), 151-162.

[9] Arigbagbuwo, A. J. (2013). Synopsis of evolution of Healthcare Providers' Association of Nigeria. The Nigerian Lancet (Quarterly Newsletter). Lagos: Healthcare Providers Association of Nigeria.

[10] Kelland, K. (2012). Doctor brain drain costs Africa \$2 Billion. BMC Health Services Research, 17 (5), 19-24.

[11] Oyewumi, O. A. \& Oyewumi, A. E. (2014). Collective bargaining in Nigeria's public health sector: evidences for an inclusive approach. Research on Humanities and Social Sciences, 4 (23). 20-26.

[12] NHIS. (2015). Annual report of the national health insurance scheme, Abuja, Nigeria. National Health Insurance Scheme.

[13] Obi, I, V, C., Okoronkwo, I, L., Azuike, E. C., Obi, K. M, \& Obi, I. R. (2019). Extent of healthcare provider adherence to national health insurance scheme (NHIS) operational guidelines: The Nigerian experience. Journal Public Administration and Governance, 1, 3 .
[14] Dalinjong, P. A., \& Laar, A. S. (2012). The national health insurance scheme: perceptions and experiences of healthcare providers and clients in two districts of Ghana. Health Economic Review, 2, 13-16.

[15] Onoka, C. A., Hanson, K., \& Mills, A. (2014). Growth of health maintenance organization in Nigeria and the potential for a role in promoting universal coverage efforts. Social Science and Medicine, 58, 70-74.

[16] NHIS. (2015). National health insurance scheme operational guidelines. Abuja, Nigeria: NHIS.

[17] Cochran, W. G. (1977). Sampling technique (3rded). New York: John Wiley \& Sons.

[18] Gertler, P., Locay, L \& Sanderson, P. (1987). Are user fees regressive? The welfare implications of health care financing proposals in Peru'. Journal of Econometrics, 36, 67-88.

[19] Ayorinde, F. O. (2009). Determination of modern healthcare facility utilization in Oyo State, Nigeria In: Applied Econometrics and Macro econometric modelling in Nigeria. Ibadan: University press University of Ibadan.

[20] Daramola, O. E., Maduka, W. E., Adeniran, A. \& Akande, T. M. (2017). Evaluation of patients, satisfaction with service accessed under the national health insurance scheme at a tertiary facility in North Central, Nigeria. Journal of Community Medicine and Primary Health Care, 29, 1.

[21] Wangen, K. R. \& Grepperud, S. (2018). Factors as determinants of treatment costs: clinicians' assessmens of a given set of referrals to community mental health centers in Norway. BMC Health Services Research, 18, 60.

[22] Haddad, G. K \& Anbaji. (2010). Analysis of adverse selection and moral hazard in the health insurance market of Iran. The International Association for the study of Insurance Economics, 35, 581-599. Health Economics, 18 (2), 141-52.

[23] Ali, K. J. \& Norman, A. N. K. (2013). Determinants of demand for healthcare in Bangladesh: an econometric analysis. World Journal of Social Sciences, 3 (6), 153-163.

[24] Oluwatayo, I. B. (2015). Healthcare service delivery system and households' welfare status in urban Southwest Nigeria. Journal of Human Ecology, 50 (2), 181-187.

[25] Ankomah, M. (2009). Reforms in the provider tariff for the NHIS: Key implementation issues. NBER working paper series, 12 (3), 7206-7209.

[26] Sleverding, M., Onyango, C. \& Suchman, L. (2011). Private healthcare provider experiences with social health insurance schemes: findings from a qualitative study in Ghana and Kenya. BMC Health Services Research, 11, 1.

[27] Spaan, E., Mathijssen, J., Tromp, N., Mcbain, F., Ten Have, A. \& Baltussen, R. (2012). The impact of health insurance in Africa and Asia: a systematic review. Bull World Health Organ, 90, 685-92.

[28] Sodzi-Tettey, S., Aikins, M., Awoonor-william, J. K. \& Agyepong, I. A. (2012). Challenges in provider payment under the Ghana medical health insurance scheme: a case study of claims management in two districts. Ghana Medical Journal, 48 (4), 189-199. 